\title{
Healthcare Problem List
}

National Cancer Institute

\section{Source}

National Cancer Institute. Healthcare Problem List. NCI Thesaurus. Code C154403.

A list of health problems or conditions compiled through healthcare encounters. 